\title{
Adding Hydrated Lime in a Material Made of Clayey Soil and Fibres: Formulation and Effects on Thermo-Mechanical Properties
}

\author{
Fati Zoma $^{1}{ }^{*}$, Fabien H. Yonli ${ }^{1}$, Etienne Malbila ${ }^{2}$, David Y. K. Toguyeni', Ivon B. Hassel ${ }^{3}$ \\ ${ }^{1}$ Laboratory of Physics and Chemistry of Environment, University Joseph KI-ZERBO, Ouagadougou, Burkina Faso \\ ${ }^{2}$ Laboratory of Thermal and Renewable Energies, University Joseph KI-ZERBO, Ouagadougou, Burkina Faso \\ ${ }^{3}$ Department of Engineering Sciences, Division of Applied Mechanics, Uppsala University, Uppsala, Sweden \\ Email: ^fatesmir@yahoo.fr
}

How to cite this paper: Zoma, F., Yonli, F.H., Malbila, E., Toguyeni, D.Y.K. and Hassel, I.B. (2020) Adding Hydrated Lime in a Material Made of Clayey Soil and Fibres: Formulation and Effects on Thermo-Mechanical Properties. Journal of Minerals and Materials Characterization and Engineering, 8, 149-161.

https://doi.org/10.4236/jmmce.2020.83010

Received: April 29, 2020

Accepted: May 25, 2020

Published: May 28, 2020

Copyright $\odot 2020$ by author(s) and Scientific Research Publishing Inc. This work is licensed under the Creative Commons Attribution International License (CC BY 4.0).

http://creativecommons.org/licenses/by/4.0/

\begin{abstract}
In this study, we have focused our investigations on effect of adding hydrated lime on a locally made composite material, based on clayey earth (soil) and Hibiscus sabdariffa fibres, for envelope (walls) in the building. Prior to sample's formulation, we selected an appropriate mineral (soil) material based on criteria as: plasticizer power for good workability, dense coarse particles to withstand loads and finally porous structure to take advantage of air insulating character. We then formulated, following a mixing process by shearing and compaction by vibration that we recommend, two composite materials (A), (B) which contain respectively $1 \%$ Fibres plus $1 \%$ lime, $1 \%$ Fibres plus $3 \%$ lime. We determined thermal properties by the mean of KD2 Pro thermal analyzer, compression strength accordingly to the standard NF P 18-406, porosity following volumetric and gravimetric methods and $\mathrm{pH}$ of soil-hydrated lime solution. As results, up to $5 \%$ of hydrated lime, the measured $\mathrm{pH}$ is inferior to 12: mineralization of vegetal fibres is highly unlikely. Moreover, we observe that the addition of hydrated lime resulted in a reduction in the number of cracks and their depths; Samples (A) and (B) have a rather compact appearance than the case $1 \%$ Fibres without lime (material (C)). Furthermore, with lime stabilization, the insulating potential is improved while the thermal inertia has been deteriorated compared to material (C). However, compressive strength decreases with lime, which could be due to the presence of fibres that would inhibit the hardening of the lime. At last, with $3.39 \% \pm$ $3.07 \% \mathrm{MPa}, 2.27 \% \pm 11.30 \% \mathrm{MPa}$ for samples (A), (B) respectively, the minimum required by CRATerre-EAG (guide of CDI, 1996) for construction of envelope (walls) of single storey (ground floor) buildings is met.
\end{abstract}




\section{Keywords}

Local Material, Hydrated Lime, Hibiscus sabdariffa Fibre, Thermo-Mechanical Properties, Porosity

\section{Introduction}

At the local level (in Burkina Faso), there are many composites used in housing construction. Since the advent of industrial materials such as reinforced concrete, which has proved to be very reliable (good resistance and rapid construction), constructions in raw earth such as adobe are increasingly neglected or even denigrated because they are seen as "constructions for the poor" or "unsustainable constructions".

However, in the current context of climate change and environmental protection, there is an interest in finding sustainable processes using local materials: it is necessary to build adapted.

Building materials based on local materials, especially earth and organic matter, are booming, as evidenced by the number and diversity of works which have been undertaken. Indeed, the Association Voute Nubienne (AVN), present in West Africa, promotes constructions with vaulted roofs and envelopes made from local materials. The work of Wyss and Sauret [1], based on the techniques disseminated by AVN [2], has shown that it is possible to obtain an acceptable level of thermal comfort without air-conditioning in case of a house made of adobe with a Nubian vault roof, in the Sahel. Also for years CRATerre, an internationally renowned association, has been working to disseminate good practices and innovations in the field of construction, specifically earthen architecture. The CRATerre-ENSAG laboratory has multiplied collaborations and published works on aspects such as technology, especially for the production of compressed earth blocks (BTC) [3] and the formulation of materials, especially the interaction between clay and polymers [4].

These various actions are sustained by investigations into the contribution of inputs of organic (vegetal and animal) and mineral origin. For instance, Ouedraogo et al. [5] studied the influence of straw (precisely Loudetia togoensis) content incorporated in blocks made of raw clayey soil. The results show that the stabilization with straw, at a straw rate of $4.81 \%$, has enabled to decrease thermal conductivity by $44.92 \%$, thermal diffusivity and thermal effusivity by $30.77 \%$ and $33.81 \%$ respectively relative to the blocks without stabilizer. Also, at the same straw rate, compressive strength has been increased by $58.96 \%$. Toukourou et al. [6] tested the variation in content (percentage) of cement and straw in compressed earth blocks. They came to the conclusion that compressed earth blocks stabilized with $10 \%$ cement and $2 \%$ straw have better thermal performance. The work of Gibibaye et al. [7] focused on another type of vegetal residue for concrete making: palm nut shells as both reinforcements and fillers. Thanks to these 
shells, they obtained a light concrete with a density varying between 1400 and $1900 \mathrm{~kg} / \mathrm{m}^{3}$ for strength of 4 to $11 \mathrm{MPa}$ depending on the volume proportions between the shells and the mineral matrix (sand). However, this resistance decreases with the increase in the percentage of shells.

However, it is not only cement that is used as a mineral input. Indeed, with the regained interest in lime and the installation of lime production units in limestone quarries, close to construction sites, lime is increasingly positioned as a good alternative to cement as a stabilizer. In the field of civil engineering, lime is recommended to improve clayey and silty soils in the context of road terracing [8]. Indeed, according to Emarah and Seleem [9] study, soil treatment with lime reduced plasticity index (P.I) by 59\% using potable water and a significant reduction in the swelling potential was achieved due to the lime stabilization process using potable water and reduction was higher in case of using sea water in the mixing process. Kennedy et al. [10] have evaluated that stabilization with lime into clayey soils of high plasticity is more effective from a point of view resistance to compression while cement treatment of low-plasticity sandy clay produced significantly higher compressive strengths than did lime treatment of this soil.

In the same theme but regarding building materials, Toukourou et al. [11] have also focused on lime by carrying out a comparative study on compressed earth blocks stabilized with cement and lime at the same percentage, i.e. $6 \%, 8 \%$ and $10 \%$. The results obtained show that compressed earth blocks stabilized with cement are more resistant and less porous than those stabilized with lime.

Moreover lime treatment provided significantly better resistance to moisture damage when these soils were compacted by the modified AASHTO compactive effort [10].

When considering materials for the building's envelope, there are other challenges besides mechanical resistance, such as comfort, physical resistance including resistance to moisture, to swelling: the use of lime could be a good compromise in masonry.

Toguyeni et al. [12] addressed the issue of static compaction's energy for building materials. In more details, they investigated formulas of compressed earth blocks regarding the following criteria: compaction energy (3 strokes or 6 strokes), stabilization with $7 \%$ hydrated lime and reinforcement of the matrix stabilized with lime with $1.4 \%$ Hibiscus sabdariffa fibres. The results showed that the variation in compaction energy, 3 strokes or 6 strokes, has no significant effect on the properties of the proposed materials. For our study, the chosen mode of compaction is vibration, the objectives being to allow a controlled and repetitive mode of compaction and to have a spontaneous rearrangement of the grains under the effect of salvation rather than forced rearrangement as is the case with static compaction.

In view of the advantages of lime and the expectations of compaction by vibration described above, our research work focuses on studying a material destined to building envelope made of hydrated lime mixed with materials from the 
1\% Fibers formula of Zoma et al. [13] work, following a compaction mode by vibration.

\section{Materials and Methods}

It is well known that inputs are intended to improve the properties of materials such as mortar or even concrete. However, the inherent characteristics of the earth material (soil), not to mention that external phenomena such as climate, have a significant impact on the final product. Therefore, on the basis of these interactions whose effects are not necessarily expected or envisaged at the outset, we have oriented our research towards formulas for materials based on lime and vegetal in order to improve both mechanical strength and thermal comfort.

Precisely, we formulated local composite materials, based on clayey earth (soil) and Hibiscus sabdariffa fibres with or without hydrated lime, for envelope (walls) in the building. We note that the case without hydrated lime, i.e. 1\% Fibers (material C), has been developed in article by Zoma et al. [13].

\subsection{Formulation}

Prior to samples' formulation, we selected an appropriate mineral (soil) material based on criteria as plasticizer power for good workability, dense coarse particles to withstand loads and porous structure to take advantage of air insulating character. So based on geotechnical requirements for an appropriate soil established by Zoma et al. [13] and standards NF P18-560, NF P94-057 AFNOR (1992), the characteristics of the chosen soil are: $48 \%$ of grains of diameter smaller than 80 $\mu \mathrm{m}$ and $52 \%$ of grains of diameter larger than $80 \mu \mathrm{m}$, with plasticity index (Ip) of $22 \%$ and methylen blue value (VB) of 6.97 [g/gs].

We then formulated, aside material (C), two composite materials (A), (B) which contain respectively $1 \%$ Fibres plus $1 \%$ lime, $1 \%$ Fibres plus $3 \%$ lime with $30 \%$ water in weigh in each; $30 \%$ water in weigh not corresponding to the optimal water content (18\%) in order to have an effective vibration.

The fibres are from Hibiscus sabdariffa plant stem, a vegetal waste, from which we got rid of the epidermis and wood. As for the lime, it is a hydrated one stocked at least seven (07) days in water and got from COVEMI's limestone quarry near Orodara, a town in South West of Burkina Faso.

The formulation was carried out as followed:

Firstly, we poured the soil material in a recipient and then vegetal fibres that were previously cut (mean length: $1 \mathrm{~cm}$ ) and soaked in water 24 hours before. Afterwards we made a homogeneous dry mixture by shearing by means of a FLOTT M3 ST drilling machine (125 rev/min) which has been provided with a finned rod (Figure 1).

At last, we poured, in the dry mixture, the water mixed with hydrated lime; then again we made a mixture and this time we made sure the mixing last for 3 minutes to ensure homogeneity of the mixture.

The resulting mixture was spilt in a mold into three (03) layers, with each layer being vibrated for five (05) seconds at $980.2 \mathrm{~Hz}$ (Figure 2). The moulds we 

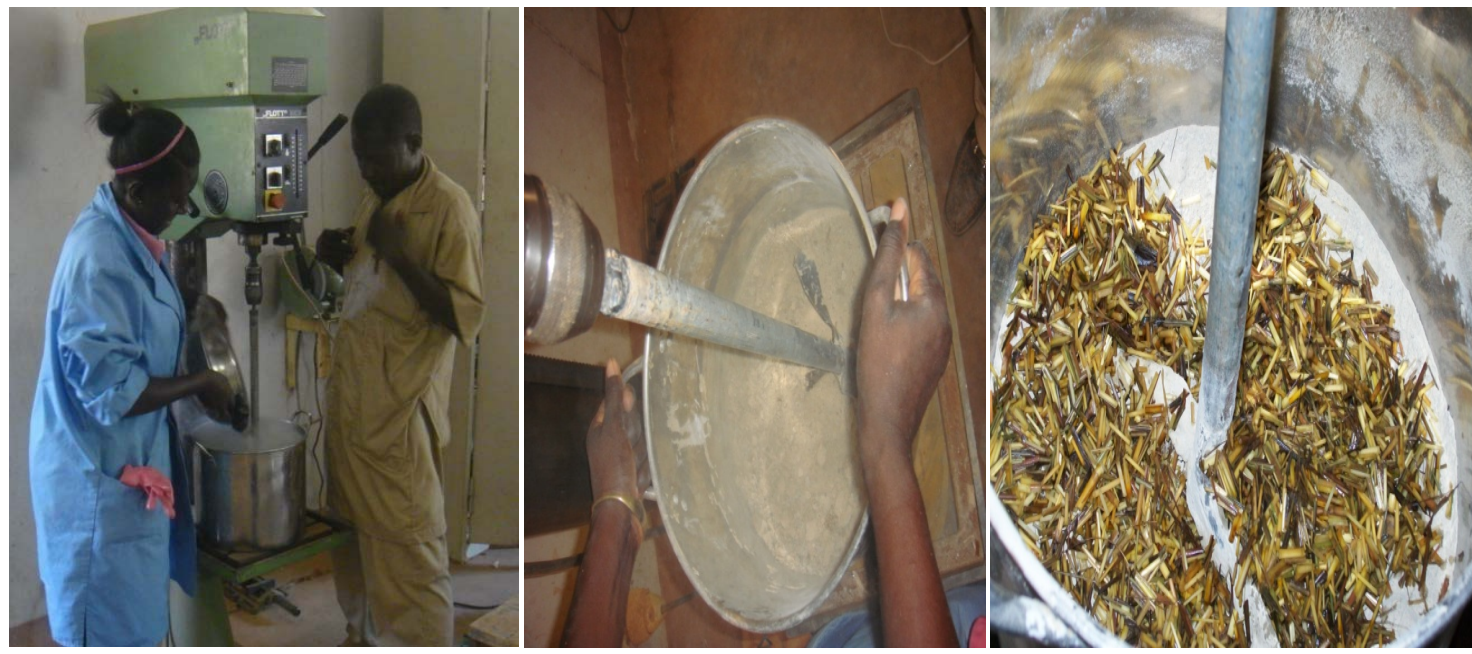

Figure 1. Mixing by shearing with a FLOTT M3 ST drilling machine which has been provided with a finned rod.

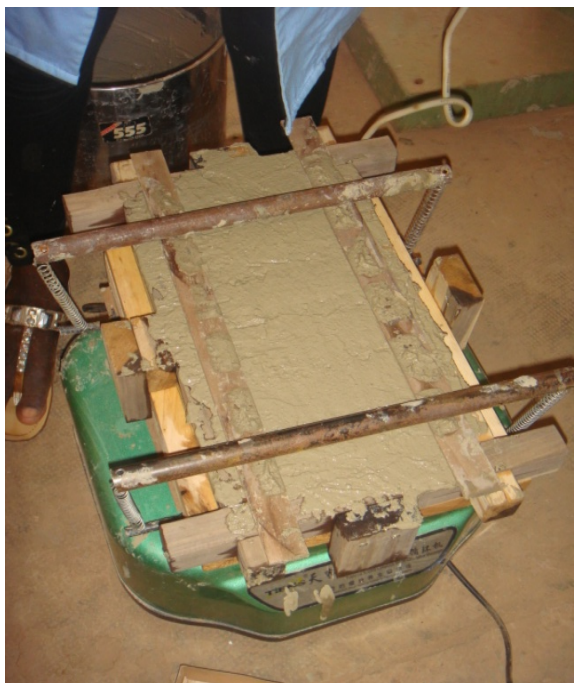

Figure 2. Vibration (5s).

used were parallelepiped shaped, cubic shaped made of wood (Figure 3 and Figure 4).

In all cases, these specimens were dried under ambient conditions (open air), covered with jute bags which we made sure to moisten every morning in order to limit rapid drying and at the same time reduce the appearance of cracks. It takes 14 days of drying (minimum) for the specimens to be compact enough for a possible test, before that, they are still wet and difficult to remove from the mould. However, it is necessary to wait at least 21 days to observe well-compacted dried specimens.

\subsection{Thermo Mechanical and Physical Characterization}

The thermal characterization was based on KD2 Pro thermal properties analyzer (Figure 5) and the compression test was conducted accordingly to the standard NF P 18-406 (Figure 6). As in the case of material (C), we also determine the 


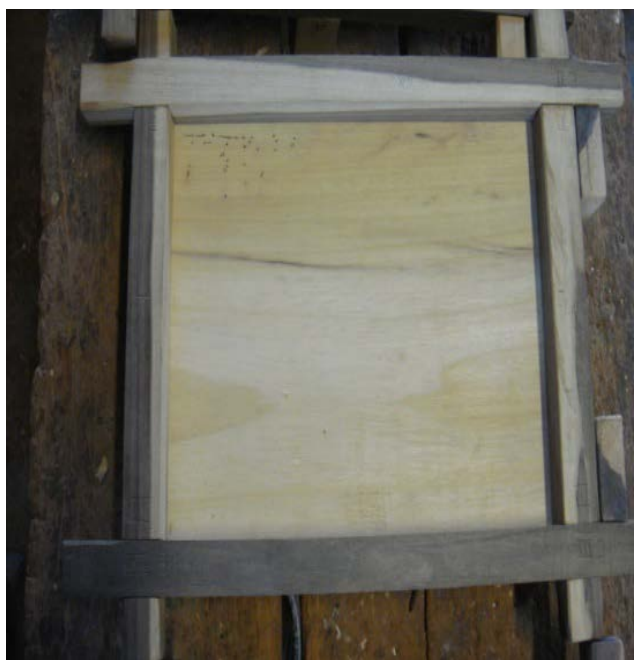

Figure 3. Parallelepipedic mould.

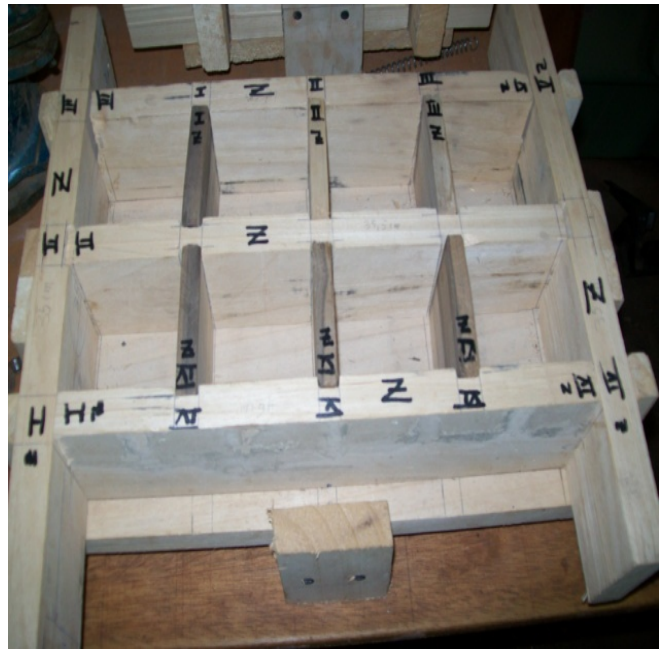

Figure 4. Cubic mould.

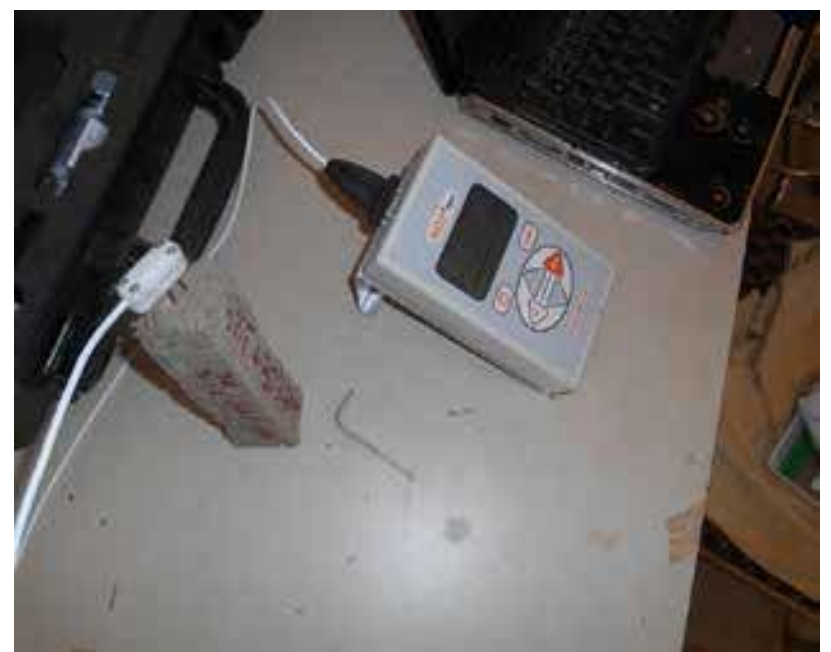

Figure 5. Thermal characterization in process with Decagon Devices KD2 Pro Thermal Properties Analyzer. 


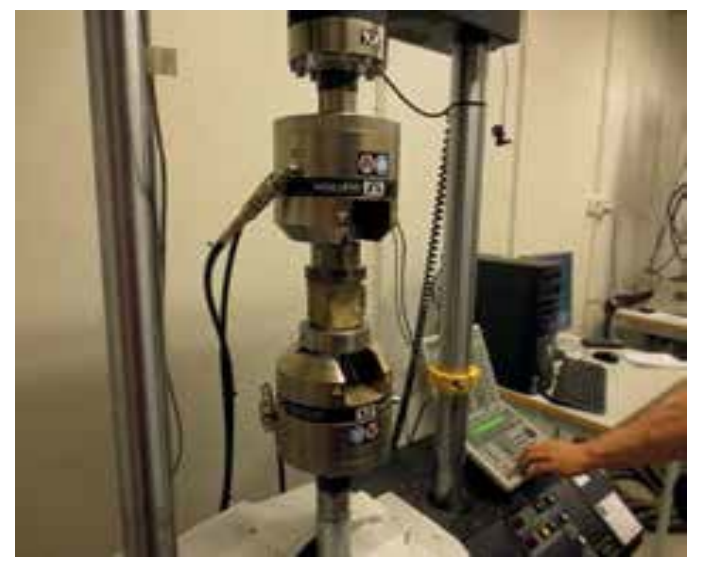

Figure 6. Compression testing on a cubic-shaped sample with an Instron 8516 machine.

porosity of materials (A) and (B) following volumetric and gravimetric methods [13].

\subsection{Potential of Hydrogen ( $\mathrm{pH})$ Test}

The mix clay-lime will be mixed into vegetal material. Therefore, in order to make sure that the vegetal material will not be degraded and then will be able to play its role, it is important to know the hydrogen potential $(\mathrm{pH})$ of the mixture. To do this, the $\mathrm{pH}$ test consisted of:

$6 \mathrm{~g}$ of raw soil paste is dissolved in one litre of sodium nitrate solution $(0.1$ $\mathrm{M})$; the sodium nitrate solution $(0.1 \mathrm{M})$ being a neutral electrolyte, i.e. the possible interactions with the chemical elements contained in the soil paste are negligible. Thus the mixture obtained is made in a flask containing a magnetic rod and then stirred with a magnetic centrifuge.

Thus the mixture obtained is made in a flask containing a magnetic rod and then stirred with a J.P. SELECTA magnetic centrifuge of type MULTIMATIC 5-N, at a mean stirring rate between 100 r.p.m and 150 r.p.m. After 15 minutes, a small quantity of the suspension is collected and the ph-meter electrode is plunged into it (Figure 7). Therefore, by digital conversion of the information received from the electrode, we read on the display of the ph-meter the value corresponding to the ph of the solution.

We note that after each reading, the electrode is plunged back into water and then cleaned with a clean cloth (e.g. toilet paper) in order to check the correct calibration of the ph-meter and also to eliminate the few possible $\mathrm{H}_{3} \mathrm{O}^{+}$ions that may still be present on the electrode.

The tests concerned the following materials:

Clayey soil; Clayey soil + $1 \%$ lime; Clayey soil $+3 \%$ lime; Clayey soil $+5 \%$ lime.

\section{Results and Discussion}

\subsection{Potential of Hydrogen ( $\mathrm{pH})$ Test Results}

Table 1 presents the results of tests to determine the $\mathrm{pH}$ of soil-hydrated lime solution depending on the lime content. 


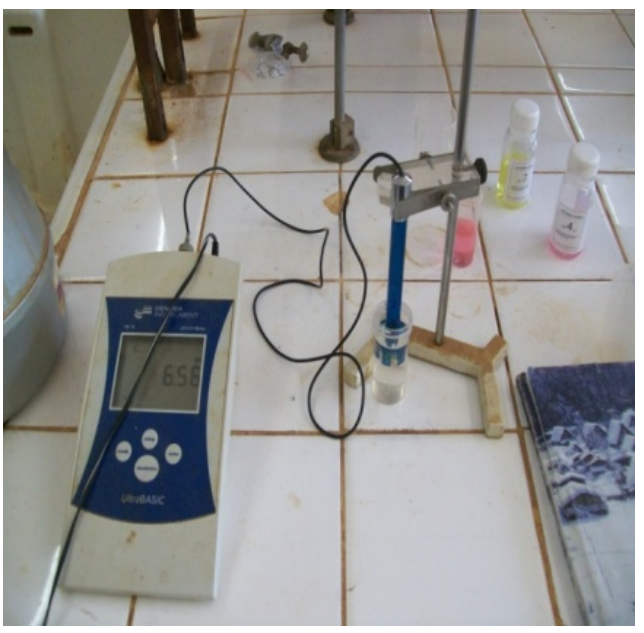

Figure 7. $\mathrm{pH}$ testing device.

Table 1. Results of $\mathrm{pH}$ measurement according to lime rate.

\begin{tabular}{ccccc}
\hline Lime rate (\% in weigh) & $0 \%$ & $1 \%$ & $3 \%$ & $5 \%$ \\
\hline $\mathrm{pH}\left(\right.$ at $\left.25^{\circ} \mathrm{C}\right)$ & 7.06 & 9.61 & 10.91 & 11.32 \\
\hline
\end{tabular}

Based on the results in Table 1, we find that the solution containing the study soil alone is a practically neutral medium and therefore will not cause any polymer degradation reaction of the vegetal material. This suggests that cellulosic materials that could be added to the mineral matrix will not lose their structural cohesion, which makes them good reinforcements [14]. The addition of lime, on the other hand, increases the $\mathrm{pH}$, which is quite normal because the hydrolysis of calcium hydroxide (slaked lime) produces hydronium ions.

However, in the presence of clay soil, lime even up to $5 \%$ does not cause high alkalinity: $\mathrm{pH}$ below 12. Although, considering that these levels of alkalinity could lead to mineralization (degradation or decomposition) of vegetal material, the mineralization would be very slow. This is what guided the choice of $1 \%$ and $3 \%$ hydrated lime in our study. However, further research is needed to verify the occurrence of mineralization of plant fibers at these alkalinity levels.

\subsection{Samples Drying}

The samples presented in this section (Figures 8-13) are the test samples for the study.

We can notice that the more there is lime in the samples the less the cracks are getting deeper, especially parallelepiped shaped samples which have a low thickness-to-length ratio (one tenth (1/10th)). Samples (A) and (B) have a rather compact appearance than $(\mathrm{C})$.

One of the characteristics of lime is that it has the power to dry the soil in which it is incorporated to make it more granular, thanks to its plasticizing character [10]. As a result, water is drawn back into the samples, hence the presence of cracks that we have observed. Furthermore, according to Maison et al. [15], 

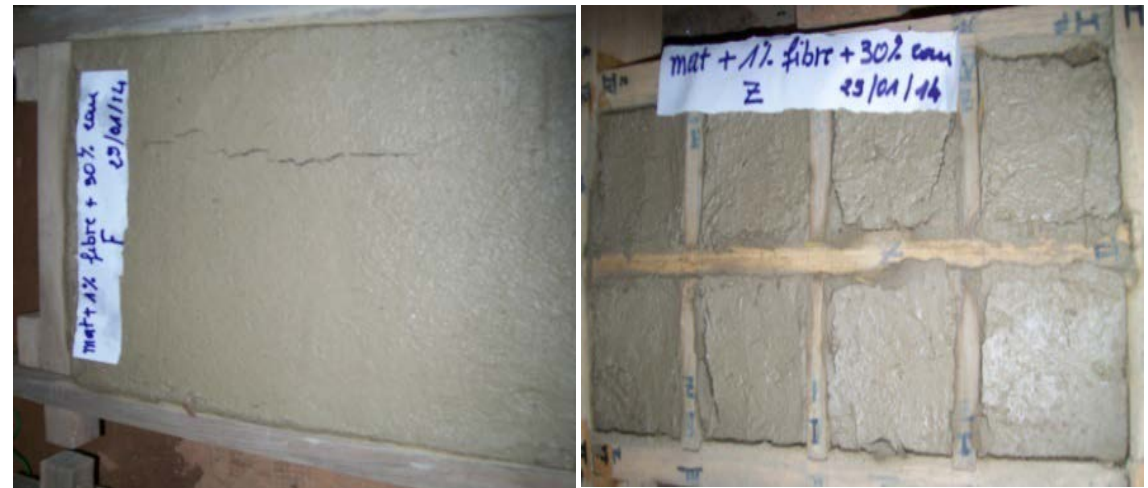

Figure 8. Sample (C) after 24 hours.
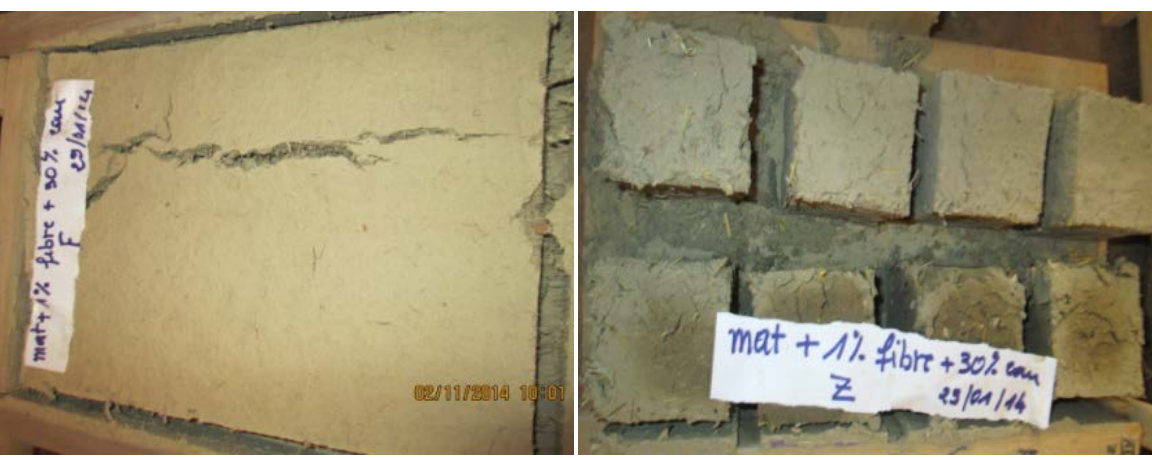

Figure 9. Sample (C) after 14 days.
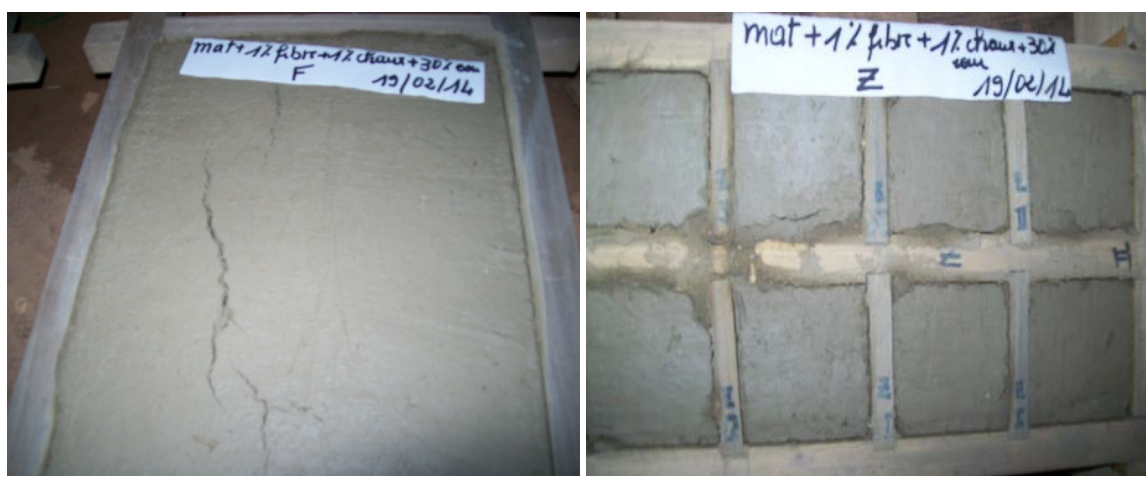

Figure 10. Sample (A) after 24 hours.
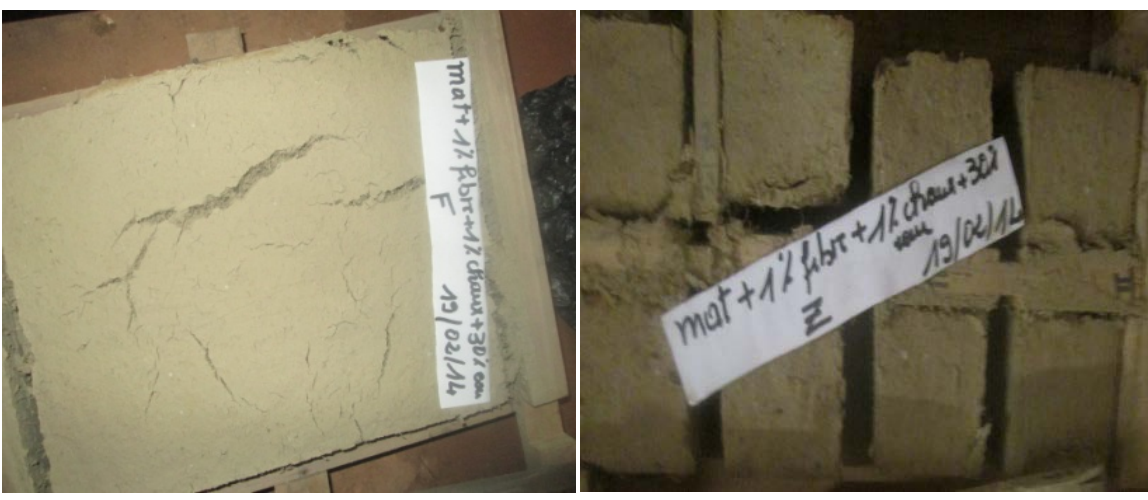

Figure 11. Sample (A) after 14 days. 

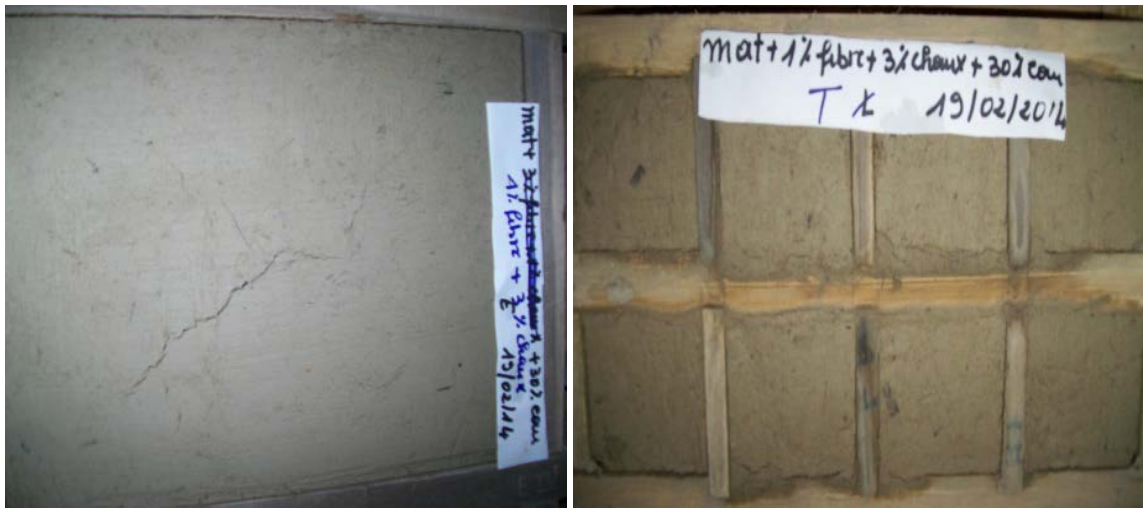

Figure 12. Sample (B) after 24 hours.
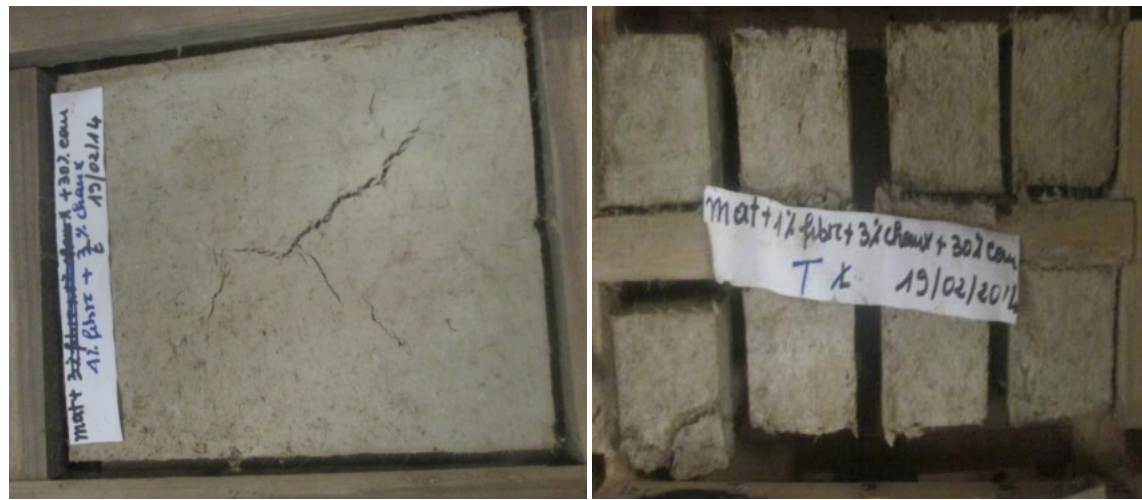

Figure 13. Sample (B) after 14 days.

even if smectites are in abundance in the clayey part of the soil, the presence of carbonates would inhibit or at least reduce the swelling phenomenon.

This indicates that the addition of lime, which is made up of calcium carbonate, reduces the phenomenon of swelling and shrinkage. Therefore, the more there is lime in the material, the less it will be subject to swelling and cracking. This would explain why in the case of $3 \%$ lime we observe fewer cracks and especially these cracks are less deep.

We also mention that these test specimens were carried out during hot periods in Burkina Faso (March, April, May).

Finally, in our regions and countryside there is a wide range of know-how from which this process is inspired [4]. However, it could bring added value in the sense that it will allow to obtain more homogeneous and compact materials thanks to shear mixing and vibratory compaction respectively.

\subsection{Characterization Results}

Table 2 shows the thermophysical properties and compressive strength of the formulated materials obtained, over a series of 3 tests each after 21 days.

As results we found out that, on one hand, adding lime (as stabilizer) seemed to mitigate thermal conductivity of the composite (C) compared to samples (A) and (B) (Table 2) which means that lime helps to enhance the insulating potential 
Table 2. Thermophysical properties and compressive strength of the studied materials.

\begin{tabular}{cccccccc}
\hline \multirow{2}{*}{ Materials } & $\rho$ & $\mathrm{k}$ & $\mathrm{C}$ & $\alpha\left(\times 10^{-7}\right)$ & $\mathrm{E}$ & $\phi$ & $\mathrm{Rc}$ \\
\cline { 2 - 8 } & {$\left[\mathrm{kg} \cdot \mathrm{m}^{-3]}\right.$} & {$[\mathrm{W} / \mathrm{m} \cdot \mathrm{K}]$} & {$\left[\mathrm{J} /{ }^{\circ} \mathrm{C} \cdot \mathrm{kg}\right]$} & {$\left[\mathrm{m}^{2} / \mathrm{s}\right]$} & {$\left[\mathrm{J} / \mathrm{m}^{2} \cdot{ }^{\circ} \mathrm{C} \cdot \mathrm{s}^{1 / 2}\right]$} & {$[\%]$} & {$[\mathrm{MPa}]$} \\
\hline (C) & $1789.48 \pm 0.08 \%$ & $0.92 \pm 5.73 \%$ & $1472.28 \pm 4.70 \%$ & $3.49 \pm 1.15 \%$ & $1556.81 \pm 5.17 \%$ & 25.36 & $3.61 \pm 8.61 \%$ \\
(A) & $1810.39 \pm 0.01 \%$ & $0.80 \pm 0.30 \%$ & $708.97 \pm 0.24 \%$ & $6.27 \pm 0.28 \%$ & $1016.06 \pm 0.21 \%$ & 28.42 & $3.39 \pm 3.07 \%$ \\
(B) & $1701.01 \pm 0.05 \%$ & $0.69 \pm 1.73 \%$ & $876.29 \pm 0.60 \%$ & $4.64 \pm 2.39 \%$ & $1015.54 \pm 0.54 \%$ & 29.17 & $2.27 \pm 11.30 \%$ \\
\hline
\end{tabular}

of material (C). The reduction corresponds respectively to $13.04 \%$ for (A) and $25 \%$ for (B) compared to material (C). These results are corroborated by the results on porosity $(\phi)$ which decreases inversely with the thermal conductivity of the studied samples. Indeed, who speaks about pores speaks about the air fluid which is known to be the best possible insulator (case of a reduced thickness and little external ventilation). Moreover, sample (C) has lower thermal diffusivity and higher thermal effusivity compared to samples containing hydrated lime. Therefore, adding hydrated lime deteriorates the thermal inertia potential of sample (C).

On the other hand, we also note that with the increase in the quantity of lime, compressive strength decreases, namely $6.09 \%$ for material (A) and $37 \%$ for material (B). This is contrary to what expected as lime, like cement, improves the compressive strength of soils [10]. However, Reading et al. [16] have shown that the impact of alkalinity is not limited to the degradation of plant fibres: the setting time of cement is also affected. Indeed, the reaction of hydronium ions on hemicelluloses for example produces elements called oligosaccharides which would prevent the cement from hardening. In other words, the presence of fibres would inhibit the hardening of the lime. This could explain these results on the compressive strength of the study samples despite the presence of lime.

At last, with $3.39 \pm 3.07 \% \mathrm{Mpa}, 2.27 \pm 11.30 \% \mathrm{Mpa}$ for samples (A), (B) respectively, the minimum required by CRATerre-EAG (guide of CDI, 1996 [3]) for construction of envelope (walls) of single storey (ground floor) buildings is met.

\section{Conclusions}

The samples in this study are the result of clay soil mortars, Hibiscus Sabdarifica cortical fibres and/or hydrated lime shear-mixed and then vibrated. It concerns material (C) containing $1 \%$ fibres to which $1 \%$ lime was incorporated (material (A)) and then $3 \%$ lime (material (B)). For the formulation of studied samples, we used Hibiscus Sabdarifica cortical fibres and hydrated lime following a process that we recommend.

Observations help find that the addition of hydrated lime resulted in a reduction in the number of cracks and their depths compared to the case without lime, which is material (C). Furthermore, with lime stabilization, the insulating capacity is improved while the thermal inertia deteriorates. In fact, on the one hand, the lowest thermal conductivity is obtained with material (B) of formula 
$1 \%$ Fibres plus $3 \%$ Lime; namely a reduction of $25 \%$ compared to material (C). On the other hand, sample (C) has lower thermal diffusivity and higher thermal effusivity compared to samples containing hydrated lime (materials (A) and (B)). Concerning the results of the compression test, they revealed that as the lime content increases, the compressive strength decreases. However, samples (A), (B) resistances meet the minimum required by CRATerre-EAG (guide of CDI, 1996) for construction of envelope (walls) of single storey (ground floor) buildings.

As a recommendation, we suggest increasing the thickness to length ratio of parallelepipedic samples in order to further reduce cracks. Moreover, as a perspective for this study, more investigations should be performed such as determination of water absorption factor, fire resistance, embodied energy and the impact on mechanical strength and cracks appearance by reducing water quantity.

\section{Acknowledgements}

We thank COVEMI for supplying us with the lime used in this study and the ISP program (Sweden) for funding a team of applied Physics researchers of University Ouaga Joseph KI-ZERBO.

\section{Conflicts of Interest}

The authors declare no conflicts of interest regarding the publication of this paper.

\section{References}

[1] Wyss, U. and Sauret, H. (2007) Comfort Indicators in the Nubian Vault Technique. Technical Report, EPFL, Nubian Vault Association, Ganges.

[2] Granier, T., Kaye, A., Ravier, J. and Sillou, D. (2006) The Nubian Vault: Earth Roofs in the Sahel. Proceedings of the Conference the Living in Hot Deserts, Ghardaïa, 9-12 December.

https://www.doc-developpement-durable.org/file/Construction-Maisons_et_routes/ vouteNubienne/AVN_paper_Ghardaia_vs2-lite.pdf

[3] Huben, H., Rigassi, V. and Gamier, P. (1996) Compressed Earth Blocks, Production Equipment. 2nd Edition, CDI \& CRATerre, Bruxelles.

[4] Vissac, A., Bourgès, A., Gandreau, D., Anger, R. and Fontaine, L. (2007) Argiles et biopolymères. CRAterre Editions, Villefontaine, France.

[5] Ouedraogo, B., Palm, K., Ouedraogo, E., Bathiebo, D. J. and Kam, S. (2016) Experimental Study of Thermophysical and Mechanical Properties of Refractory Clay Tilled into Straw-Fiber Stabilized Blocks. Physical Science International Journal (PSI), 12, Article No. PSIJ.29586. https://doi.org/10.9734/PSIJ/2016/29586

[6] Toukourou, C.A., Ahouannou, C., Monteiro, R.A. and Avamass, S.J. (2013) Determination of the Thermophysical Characteristics of the Earth-Cement Straw Composite Material: Application to Compressed Earth Bricks. Proceedings of the Conference: Eco-matériaux de construction: pilier de la croissance verte en Afrique?, Ouagadougou, 10-12 June 2013. (Unpublished) 
[7] Gibibaye, M. and Godonou, G. F. (2018) Mixture Proportioning for Oil Palm Kernel Shell. In: Palm Oil, Viduranga Waisundara, 133-146.

https://doi.org/10.5772/intechopen.75601

[8] (2004) Code De Bonne Pratique pour Le Traitement Des Sols à La Chaux et/ou au Ciment, Recommandations R 74/04. Centre de recherches routières, Bruxelles.

[9] Emarah, D.A. and Seleem, S.A. (2017) Swelling Soils Treatment Using Lime and Sea Water for Roads Construction. Alexandria Engineering Journal, 57, 2357-2365. https://doi.org/10.1016/j.aej.2017.08.009

[10] Kennedy, T.W., Smith, R., Holmgree Jr., R.J. and Tahmoressi, M. (1987) An Evaluation of Lime and Cement Stabilization. Transportation Research Board, No. 1119, 11-25. http://onlinepubs.trb.org/Onlinepubs/trr/1987/1119/1119-002.pdf

[11] Toukourou, C.A., Zevounou, C., Yamonche, A. and Assogba, Z.F. (2013) Comparative Study of Mechanical Compressed Earth Blocks Stabilized Case: Stabilization With Lime and Cement. Proceedings of the Conference: Eco-matériaux de construction: Pilier de la croissance verte en Afrique? Ouagadougou, 10-12 June. (Unpublished)

[12] Toguyeni, D.Y.K., Lawane, A., Zoma, F. and Khamis, G. (2018) Formulation of Compressed Earth Blocks Stabilized with Lime and Hibiscus sabdariffa Fibres Showcasing Good Thermal and Mechanical Properties. Journal of Materials Science \& Surface Engineering (JMSSE), 6, 817-824.

[13] Zoma, F., Toguyeni, D.K.Y., Coulibaly, O., Hassel, I. and Ouedraogo, A. (2018) Potentials of an Eco-Friendly Composite in Hot-Dry Climate. Journal of Renewable Materials, 6, 47-54. https://doi.org/10.7569/JRM.2017.634147

[14] Sedan, D. (2007) Study of the Physico-Chemical Interactions at Hemp Fibre/Cement Interfaces, Influence on the Mechanical Properties of the Composite. Ph.D. Thesis, University of Limoges, Limoges.

[15] Maison, T., Laouf, F., Fleureau, J.M. and Delalain, P. (2009) Analysis at Micro and Macroscopic Scales of the Drying and Swelling Mechanisms of Clayey Soils. Proceedings of the 19th French Congress of Mechanics, Marseille, 24-28 August 2009, 1-6.

[16] Reading, T.J. (1985) Deleterious Effects of Wood Forms on Concrete Surfaces. Concrete International, 7, 57-62. 